\title{
Vocal behaviour and neighbour spatial arrangement during vocal displays in eagle owls (Bubo bubo)
}

\author{
M. M. Delgado \& V. Penteriani \\ Department of Conservation Biology, Estación Biológica de Doñana, CSIC, Seville, Spain
}

\author{
Keywords \\ vocal behaviour; animal communication; core \\ area; call posts; Bubo bubo; eagle owl. \\ Correspondence \\ Maria del Mar Delgado, Department of \\ Conservation Biology, Estación Biológica de \\ Doñana, CSIC, Avda. de María Luisa s/n, \\ Pabellón del Perú, Apdo 1056, 41013 \\ Seville, Spain. \\ Email: mmdelgado@ebd.csic.es
}

\begin{abstract}
We quantified temporal and spatial patterns of adult eagle owl Bubo bubo vocal behaviour throughout an entire year. The duration of adult eagle owl vocal displays showed significant differences during different periods of the year: there was one major peak in the pre-laying period, when duets of mates were also more frequent. The daily distribution of adult vocalizations showed a similar pattern among the different periods, with vocal activity being most intense at sunset and sunrise. Analyses of the characteristics of call posts showed that the choice of such focal points was guided by the trade-off between the need to defend the territory and within-pair communication inside the core areas, as well as efficient communication with neighbours.
\end{abstract}

\section{Introduction}

Patterns of bird vocal display depend upon many different external factors, one of the most important being social contexts (e.g. Marler \& Slabbekoorn, 2004). In particular, many studies have been directed at matched countersinging (e.g. Krebs, Ashcroft \& Orsdol, 1981; Simpson, 1985; Hyman, 2003), mate and neighbour recognition (e.g. McGregor \& Avery, 1986; Stoddard et al., 1991; Temeles, 1994; Molles \& Vehrencamp, 2001), song structure (e.g. Galeotti et al., 1997; Nicholls \& Goldizen, 2006) and temporal patterns of intraspecific vocal communication (e.g. Popp, 1989; McGregor, 2005). In these communication networks, territorial birds vocally interact to gain information about the features of neighbours and delimit their territory (McGregor, 1993, 2005; McGregor \& Peake, 2000).

Despite the large number of studies on vocal behaviour, spatial patterns of vocal displays are generally poorly known (especially in nocturnal species), mainly due to the difficulty in simultaneously recording the exact location of individuals involved in communication networks when they are not radio-tagged. Moreover, when studying spatial patterns of vocal behaviour, we need to pay attention to the complex movement patterns that can result from the interactions between individuals and their environment. Patterns of home-range use (Moorcroft, Lewis \& Crabtree, 1999; Belisle \& St Clair, 2001) and community interactions (Ellner et al., 2001) are some examples of such interactiondependent movements. Over the last decades, many studies have analysed home-range size, shape and spatial-use patterns, showing that individuals use space disproportionately within the boundaries of their home range (Adams \& Davis, 1967; Dixon \& Chapman, 1980; Samuel, Pierce \& Garton, 1985). In fact, the whole home range is not equally important for its owners, with some areas being used more than others. Such areas (i.e. core areas; Samuel et al., 1985) receive the bulk of territorial activity because they surround the nest or are within hunting areas. These areas of intense use usually contain home sites, refuges and the highest availability of food (Burt, 1943; Kaufmann, 1962; Ewer, 1968). Although home-range overlaps are common (Hayward, Hayward \& Garton, 1987; Nicholls \& Fuller, 1987; Belthoff, Sparks \& Ritchison, 1993; Melis, Cagnacci \& Lovari, 2005), core areas of neighbouring individuals usually show exclusive owner occupation (Ewer, 1968; Samuel et al., 1985).

In long-lived monogamous species, in which pair bonds and territories are maintained year-round and can persist over several years, space use and vocal displays may show strong interactions. Such interactions may increase because of constant pressures represented by the year-round presence of both neighbours and intruders (e.g. Bradbury \& Vehrencamp, 1998; Hall, 2000; Penteriani, 2002). In fact, conspecific density is an important factor affecting territorial behaviour and spatial patterns of movements and habitat use (e.g. Fretwell \& Lucas, 1970; Parker, 1974; Alexander, 1975; Danielson, 1992; Ruxton, Armstrong \& Humphries, 1999; Penteriani, 2003).

In this study, we analysed call behaviour in the eagle owl Bubo bubo, a long-lived species characterized by both strong 
territoriality and pair bonds in which territorial defence is mainly performed by males (Penteriani, 2002, 2003). Eagle owl vocal behaviour is associated with intra- and intersexual territorial disputes, as well as with courtship behaviour (Penteriani, 2002). This species represents an interesting model to study particularly unknown aspects of bird vocal communication for two specific characteristics: (1) There is a white badge on the throat, visible only during call displays when the throat is repeatedly inflated/deflated at each call (Penteriani et al., 2006). It seems that such a trait is associated with visual communication in this species (Penteriani et al., in press). (2) The species can attain very high density (in our study population: 35 breeding pairs per $100 \mathrm{~km}^{2}$ ), favouring complex spatio-temporal individual interactions.

The aims of this work were twofold. Firstly, we investigated the seasonal and daily variations of vocal behaviour throughout the year. We hypothesized that (1) because of territorial/mating functions of calls (Penteriani, 2002), the highest rates of vocal display should occur during the prelaying period, and (2) because of the presence of evident visual traits associated with vocal signalling, an important part of the vocal behaviour should occur at sunset and sunrise, when specific conditions of ambient light favour signalling by achromatic patches (Penteriani et al., in press). Secondly, we studied the spatial arrangement of call posts within the home range mainly in relation to (1) location of core areas and neighbours and (2) both visual and vocal signalling needs. In fact, we hypothesized that locations of call posts should reflect a trade-off between territorial defence and within-pair communication inside core areas and efficient communication with neighbours (both vocal and visual).

\section{Materials and methods}

\section{Study area}

The present study was conducted in the Sierra Norte (Sierra Morena massif), $20 \mathrm{~km}$ north of Seville (south-western Spain; for more information see Penteriani et al., 2005).

\section{Patterns of daily and seasonal vocal behaviour}

Vocal displays of 15 eagle owl breeding pairs were studied in listening sessions from 1 January to 31 December 2004. We recorded the frequencies and temporal distribution of the main eagle owl calls (Penteriani, 1996) for both males and females, that is (1) the typical hoot of adults (i.e. oohu, easily distinguishable between sexes) and (2) the three most frequent additional calls (kvék, wäha and gräck).

For the daily listening sessions, and following Penteriani (1999, 2001), (1) we divided the overall study period into blocks of 20 days; (2) listening sessions started $1 \mathrm{~h}$ before sunset and ended $1 \mathrm{~h}$ after sunrise; (3) for each night within the 20-day interval, we computed the number of minutes in the listening sessions night and equally distributed them (on a rotational basis) among the 15 pairs. Within each time slot, we recorded the following data for each call type (for both males and females): (1) time of the first and last call of the night; (2) duration of vocal bouts (e.g. series of single oohu, determined by a stopwatch); we defined the end of a series of such a bout as the last call heard $\mathbf{4 6 0} \mathrm{s}$ before the next call (i.e. 1 min of silence between calls was regarded as a dividing unit of time); a value of $1 \mathrm{~s}$ was arbitrarily ascribed to one isolated call; (3) number of calls within each series. Because we found a positive correlation between (1) the duration of individual calls and call number throughout the year for both males $(r=0.94$, PO0.0001) and females $\left(r_{s}=0.85, P O 0.0001\right)$ and (2) the duration of alarm calls and the number of calls per vocal display $\left(r_{s}=0.87\right.$, PO0.0001), only duration was used for analyses.

The nights of the listening sessions corresponding to the 20-day blocks were ascribed to the following different periods of the annual breeding cycle: incubation (midJanuary-mid-March), nestling (late March-early April), fledging and post-fledging dependence (mid-April-August) and territorial/courtship (hereafter, pre-laying period; i.e. the period between the beginning of juvenile dispersal to egg laying; September-early January). As significant changes in the breeding cycle might interfere with vocal activity patterns (e.g. egg loss or nestling death), and also to avoid recording call rates that differed due to possible breeding asynchrony among neighbouring pairs (a frequent phenomenon in this species), the progress of reproduction was systematically checked in each site during the breeding period. Because conspecific density affects call rate and duration of vocal displays (Penteriani, 2003), our sample of owl pairs was chosen within an area of homogeneous density.

One-way ANOVAs tested (1) the duration of vocalizations for each period of the annual breeding cycle and (2) the distribution of the vocal displays among the hourly blocks. Because of their non-normal distribution, vocalization of females and alarm calls were analysed by non-parametric statistics. Finally, a $w^{2}$ tested the distribution of duets during the four periods of the annual breeding cycle.

\section{Features and spatial distribution of call posts}

We located the positions of 114 call posts for a sample of 19 breeding males (the ones from the 15 pairs for which we analysed year-long vocalizations + four neighbouring males) both during listening sessions and by radio-tracking six adult males. The localization of the call posts of nontagged males was only possible when the bird was (1) visible (e.g. during full moon nights or when the call post was in an open surrounding) or (2) quite close to be correctly located by call listening only.

Radiotagged owls were equipped with $30 \mathrm{~g}$ harness mounted backpacks (Biotrack Ltd, Wareham, Dorset, UK), with a mercury posture sensor that allowed us to record the rhythms of activity during the night. Locations of radio-marked animals were determined by triangulation 
using three-element hand-held Yagi antennas (Wareham, UK) with Stabo (XR-100) portable receivers (Osaka, Japan), from $1 \mathrm{~h}$ before sunset to $1 \mathrm{~h}$ after sunrise. We performed continuous radio-tracking (e.g. a single owl was followed during the whole night) three times a week throughout the entire year.

For each call post, we first plotted the location on 1:10 000 maps using a global positioning system. Secondly, to avoid pseudoreplication, we randomly selected three posts $(n=57)$ within each home range; that is the minimum number we were able to collect for each pair. Finally, we calculated the distances of the three call posts to (1) all the known call posts of the same individual, (2) the nest occupied during that breeding season, and (3) the call posts of the nearest neighbour. We used the extension 'Nearest Features v. 3.6 d' (Jenness, 2002) to calculate the above cited distances.

For analyses on the spatial arrangement of call posts within the male home range, we only used the call posts recorded by the radio-tagged males. In fact, only by following such individuals were we able to record the whole set of call posts used by an owl. For this analysis, and because of the need to depict the real distribution of call posts within the home range, the whole set of such posts was used. Although the mean eagle owl home range in our study area is quite small (c. 270 ha), our listening sessions were conducted close to nest sites. As such, we may not have included posts at the border of the home range. The features and spatial distribution of call posts were analysed by GIS software ArcView 3.2.

To verify whether call posts were randomly distributed or not, we used two approaches. Firstly, we estimated the home ranges, also identifying 50, 75 and $95 \%$ core areas. The outline method used for describing internal range structure was adaptative kernel contouring (Worton, 1989). We used least-squares cross validation (LSCV) to select the smoothing width because it minimizes the estimated error for a given sample (Silverman, 1986). This method was generated by the extension 'home range' (Rodgers \& Carr, 2002). Information on the home-range characteristics was used to (1) compare the area delimited by the call posts with the whole home range [using minimum convex polygon (MCP); Hayne, 1949] and (2) calculate the distances between each post and the outlines of core(s). Secondly, and to determine whether eagle owls should select call posts with the aim of optimizing social communication (Møller, 1988; Beck \& Luke George, 2000), we compared the coefficient of dominance (Gainzarain, Arambarri \& Rodriguez, 2000) of one randomly chosen call post with one random location within the area delimited by the call posts per owl $(n=19)$. 'Animal movement' extension (Hooge \& Eichenlaub, 1997) generated all random locations.

Call posts were analysed using t-tests and one-way ANOVAs. Distances for each call post to core outlines were log transformed to achieve a normal distribution. Means were given $\mathrm{T}$ sD, tests were two-tailed, and statistical significance was set at P Ç 0.05. Software packages were STATISTICA and SPSS 10.0.

\section{Results}

\section{Patterns of daily and seasonal vocal behaviour}

The duration of both male and female calls varied considerably among the four different periods of the year (males: $\mathrm{F}_{3,54}=2.70, \mathrm{P}=0.05$; females: $\mathrm{H}=14.52, \mathrm{P}=0.002$, d.f. $=3$, Kruskal-Wallis; Table 1). The longest vocal displays occurred during the pre-laying period, whereas the shortest vocal activity was recorded during the incubation and fledging periods for females and males, respectively (Fig. 1). During the pre-laying period, we also recorded (Fig. 2) (1) the highest amount of widely distributed call peaks during the entire night and (2) the shortest time interval between two consecutives series of bouts (Table 1). The first and last calls of males were always uttered relatively close to sunset (ranging from $29 \mathrm{~min}$ before to $145 \mathrm{~min}$ after sunset) and sunrise (ranging from $60 \mathrm{~min}$ before to $55 \mathrm{~min}$ after sunrise), respectively. However, during the fledging and post-fledging dependence period, the last call was always recorded before sunrise (from 2 to $60 \mathrm{~min}$ before).

Females also showed their peak of vocal activity during the pre-laying period, when duets were also more frequent $\left(w^{2}=364.5\right.$, d.f. $=3$, Po 0.0001). Unlike males, vocal events of females were less related to sunset and sunrise (Fig. 2). Although the vocal activity of females was lower than that

Table 1 Characteristics of eagle owl Bubo bubo vocal activity $(n=15$ pairs) during the year

\begin{tabular}{|c|c|c|c|c|c|c|c|c|}
\hline \multirow[t]{2}{*}{ Period } & \multicolumn{2}{|l|}{ Incubation } & \multicolumn{2}{|l|}{ Nestling } & \multicolumn{2}{|l|}{ Fledging } & \multicolumn{2}{|l|}{ Pre-laying period } \\
\hline & Males & Females & Males & Female & Males & Females & Males & Females \\
\hline \multicolumn{9}{|l|}{ Call characteristics } \\
\hline Duration of vocal displays (s) & $\begin{array}{r}371.7 \text { T } 266.9 \\
(26-761.5)\end{array}$ & $\begin{array}{l}4.3 \mathrm{~T} 3.7 \\
(1.5-8.5)\end{array}$ & $\begin{array}{r}198.6 \mathrm{~T} 180.4 \\
(8-567.5)\end{array}$ & $\begin{array}{l}175 \\
(175)\end{array}$ & $\begin{array}{r}177.7 \text { T } 93.0 \\
(1-243.8)\end{array}$ & $\begin{array}{r}15.8 \top 14.9 \\
(0.9-39.7)\end{array}$ & $\begin{array}{l}330.5 \text { T } 284.8 \\
(23.95-1099.5)\end{array}$ & $\begin{array}{l}34.9 \text { T } 35.9 \\
(0.14-103.4)\end{array}$ \\
\hline Calls per bout series & $\begin{array}{c}36.1 \text { T } 25.6 \\
(4.5-73)\end{array}$ & $\begin{array}{r}1.3 \mathrm{~T} 0.3 \\
(1-1.5)\end{array}$ & $\begin{array}{r}21.6 \mathrm{~T} 18.7 \\
(1.5-52.5)\end{array}$ & $\begin{array}{l}11 \\
(11)\end{array}$ & $\begin{array}{c}10.23 \mathrm{~T} 7.1 \\
(1-18)\end{array}$ & $\begin{array}{r}1.4 \mathrm{~T} 0.3 \\
(1-1.9)\end{array}$ & $\begin{array}{l}32.8 \mathrm{~T} 30.3 \\
(2.1-117.7)\end{array}$ & $\begin{array}{l}8.06 \text { T } 8.6 \\
(0.14-23.3)\end{array}$ \\
\hline $\begin{array}{l}\text { Minimum time interval } \\
\text { (min) }\end{array}$ & $\begin{array}{c}20.1 \text { T } 52.9 \\
(1-345)\end{array}$ & $\begin{array}{c}266.0 \text { T } 202.1 \\
(56-447)\end{array}$ & $\begin{array}{c}56.3 \text { T } 91.4 \\
\quad(1-340)\end{array}$ & $\begin{array}{l}0.0 \mathrm{~T} 0.0^{\mathrm{a}} \\
(0-0)\end{array}$ & $\begin{array}{c}35.8 \mathrm{~T} 81.5 \\
(1-415)\end{array}$ & $\begin{array}{c}14.6 \mathrm{~T} 23.0 \\
(1-65)\end{array}$ & $\begin{array}{l}28.0 \mathrm{~T} 60.7 \\
\quad(1-401)\end{array}$ & $\begin{array}{c}52.3 \mathrm{~T} 135.3 \\
(1-669)\end{array}$ \\
\hline
\end{tabular}

${ }^{\mathrm{a}}$ There is no minimum time interval because during nestling we only recorded one series of $175 \mathrm{~s}$ and 11 calls per series of bouts.

The duration (s) represents the mean T SD, minimum and maximum call length of the different periods of the annual breeding cycle. Time intervals are calculated as the latency between two successive series of bouts. 
of males throughout the year $(n=47,22 ; \mathrm{Z}=-5.05$, Po 0.0001, Mann-Whitney U-tests), there was a positive association between vocal display patterns of both sexes $\left(r_{\mathrm{s}}=0.481\right.$, PO0.0001; Fig. 1).

We found a difference in the duration of alarm calls during the pre-laying period (41.62 T 55.46 s) compared with the whole year (1.25 T $4.90 \mathrm{~s} ; \mathrm{Z}=-5.1$, PO0.0001). A total of $70.7 \%$ of the alarm calls were preceded and/or followed at a Ç 1-min interval by one call or a series of main calls, whereas in the remaining $29.3 \%$ alarm calls represented isolated vocalization.

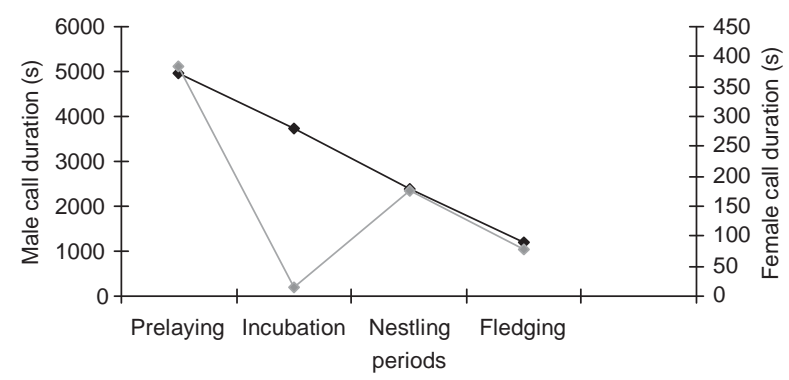

Figure 1 Total duration of vocal displays of male (black line) and female (grey line) eagle owls Bubo bubo during the four main periods of the year: incubation, nestling, fledging/post-fledging and pre-laying periods.

\section{Features and spatial distribution of call posts}

Call posts $(n=57)$ of individual owls were located with a mean distance of (1) $232.1 \mathrm{~T} 244.4 \mathrm{~m}$ (range $=1.5-1133.6 \mathrm{~m}$ ) between them, (2) $332.4 \mathrm{~T} 202.7 \mathrm{~m}$ (range $=26.2-1140.5 \mathrm{~m}$ ) to the nest and (3) $1156.2 \mathrm{~T} 358.5 \mathrm{~m}$ (range $=125.0-2515.3 \mathrm{~m}$ ) from the call posts of the nearest-neighbour male.

We found that the area delimited by the different call posts of individual owls (29.5 T $24.7 \mathrm{ha})$ was significantly different $(\mathrm{t}=3.64$, d.f. $=16, \mathrm{P}=0.002)$ from the total extension of the home range ( $\mathrm{MCP}=174.8 \mathrm{~T} 117.2 \mathrm{ha}$ ), being only $16.9 \%$ of the extension of the latter. The distances between the call posts of a male and its nearest core border (for 50, 75 and 95\% core areas) differed significantly $\left(F_{2,112}=27.35\right.$, PO0.0001), being shorter from the $95 \%$ core area. That is, call posts tended to be concentrated within the most used portion of male home ranges (Fig. 4). Moreover, the position of call posts was found to be inversely correlated with the distance to the call posts of the nearest-neighbour male $\left(\mathrm{r}_{\mathrm{s}}=-0.40, \mathrm{P}=0.008\right.$; Fig. 3$)$, that is the more distant the call post of a male from its core area, the closer this call post to the call post of the nearestneighbour male (Fig. 5). Finally, call posts tended to be higher (31.4 T $16.5 \mathrm{~m})$ than corresponding random locations (13.0 T $10.4 \mathrm{~m}, \mathrm{t}=4.10$, d.f. $=36$, PO0.0001).
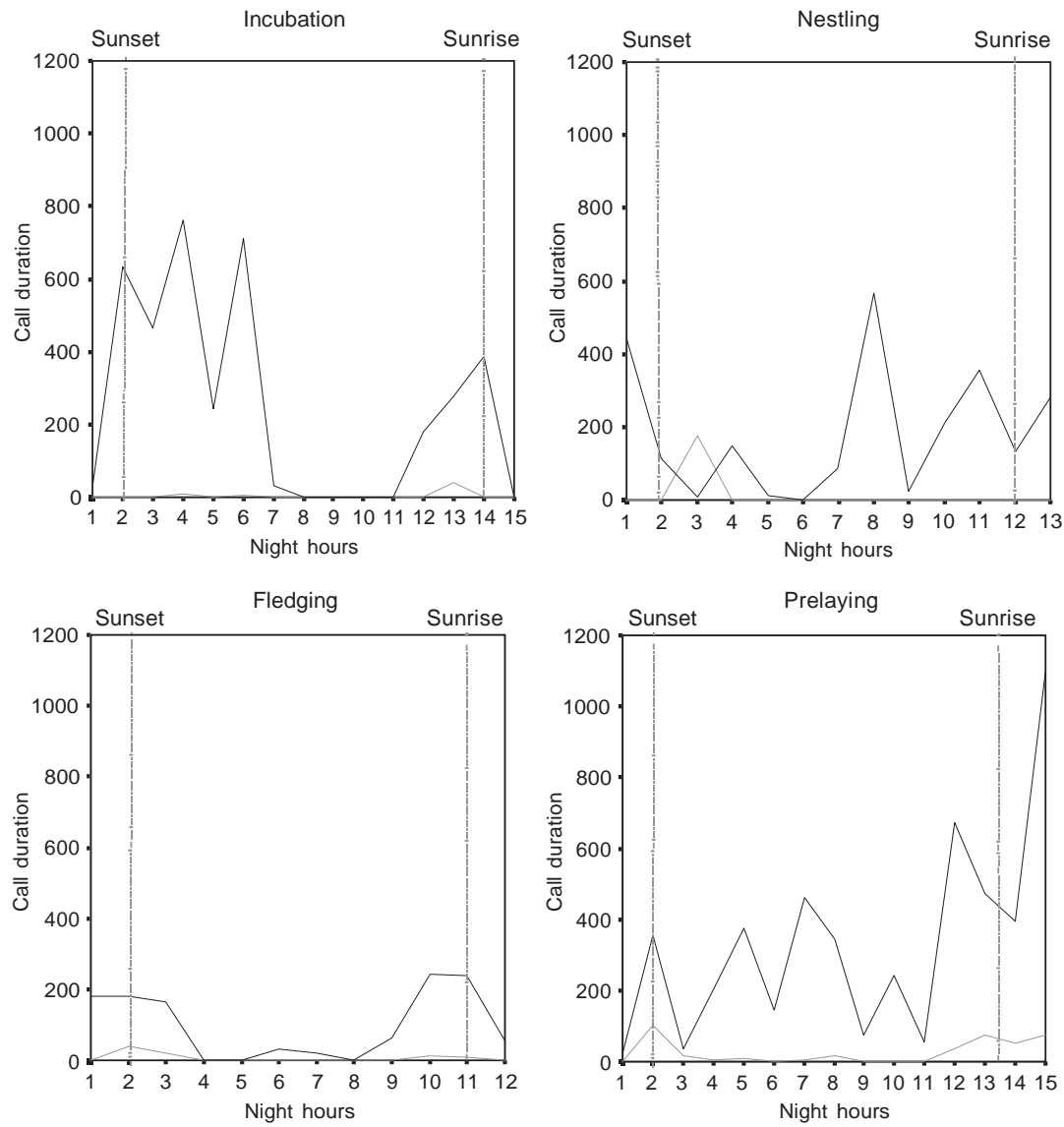

Figure 2 Total duration of male (black line) and female (grey line) eagle owl Bubo bubo calls during the whole night and for the incubation, nestling, fledging/post-fledging and pre-laying periods. Vertical lines show sunset and sunrise. The longest and widely distributed call displays were recorded during the pre-laying period (September-early January in our study area). The duration of the night (i.e. night hours) is different due to seasonal variations. 


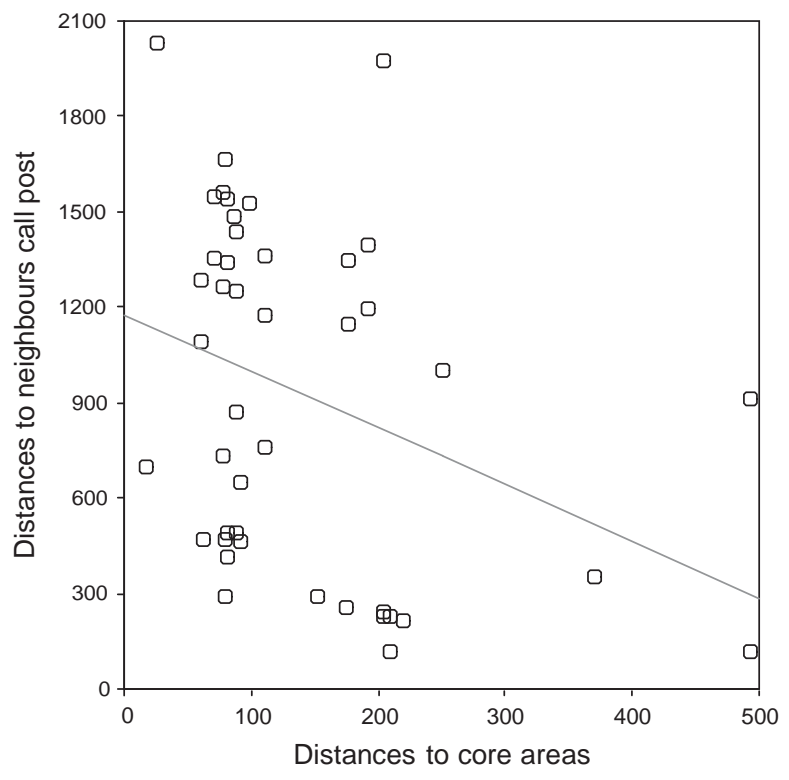

Figure 3 The position of call posts within the core areas showed an inverse correlation with the distance to the call posts of the nearest neighbours. That is, eagle owl Bubo bubo call posts are distributed to both mark their core areas and enhance conspecific communication with neighbouring males.

\section{Discussion}

\section{Vocal behaviour}

Although adult eagle owl vocalizations occurred throughout the year, the duration of vocal events was highest during the pre-laying period (September-January). In this period duets of mates are frequent and calling activity, as predicted, seems to be related to both territoriality and intrapair communication. Previous owl studies (Marshall, 1967; Voous, 1988; Klatt \& Ritchison, 1993) have suggested that duetting plays a role in the establishment, or re-establishment, of pair bonds. Because females showed their peak of vocal activity in this period only, whereas males showed high call rates through the whole year, we can hypothesize that territoriality is largely shown by males, whereas female calling appears mainly related to mate communication.

The high frequency of the alarm call during the pre-laying period and the fact that $70.7 \%$ of these calls were always preceded and/or followed by pair contact suggested that the meaning of this call is not simply an alarm call necessarily related to stress or defence but also to high excitement during mate contacts (see also Penteriani, 2001). Moreover, during reproductive seasons, aggressive calls may also express sexual conflicts (Davies, 1989).

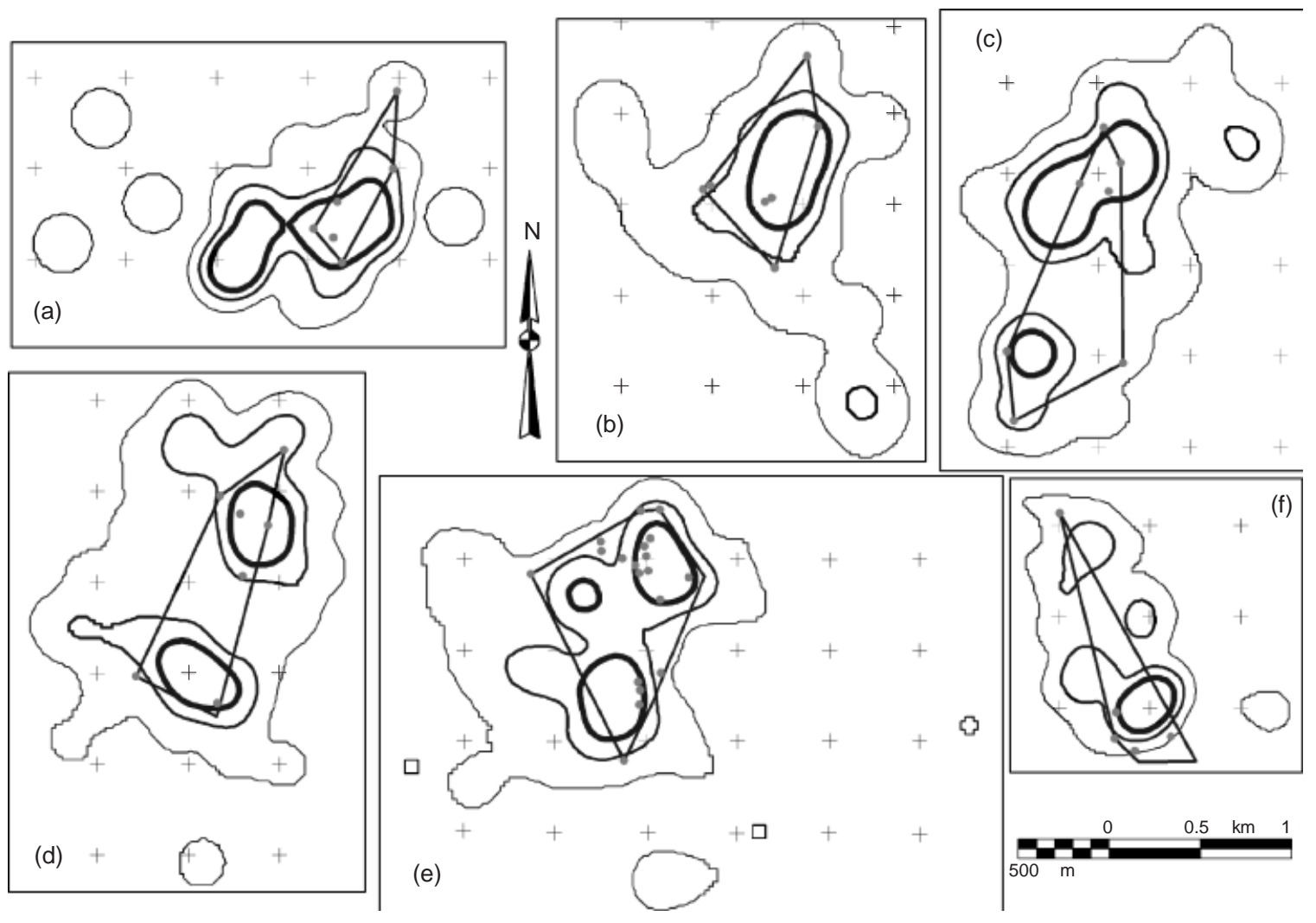

Figure 4 Within an eagle owl Bubo bubo home range $(n=6)$, call posts mainly delimited the core areas. Contours represent 50,75 and $95 \%$ (from tighter to bolder line, respectively) of the core area utilization distribution, whereas dots indicate call-post locations. 


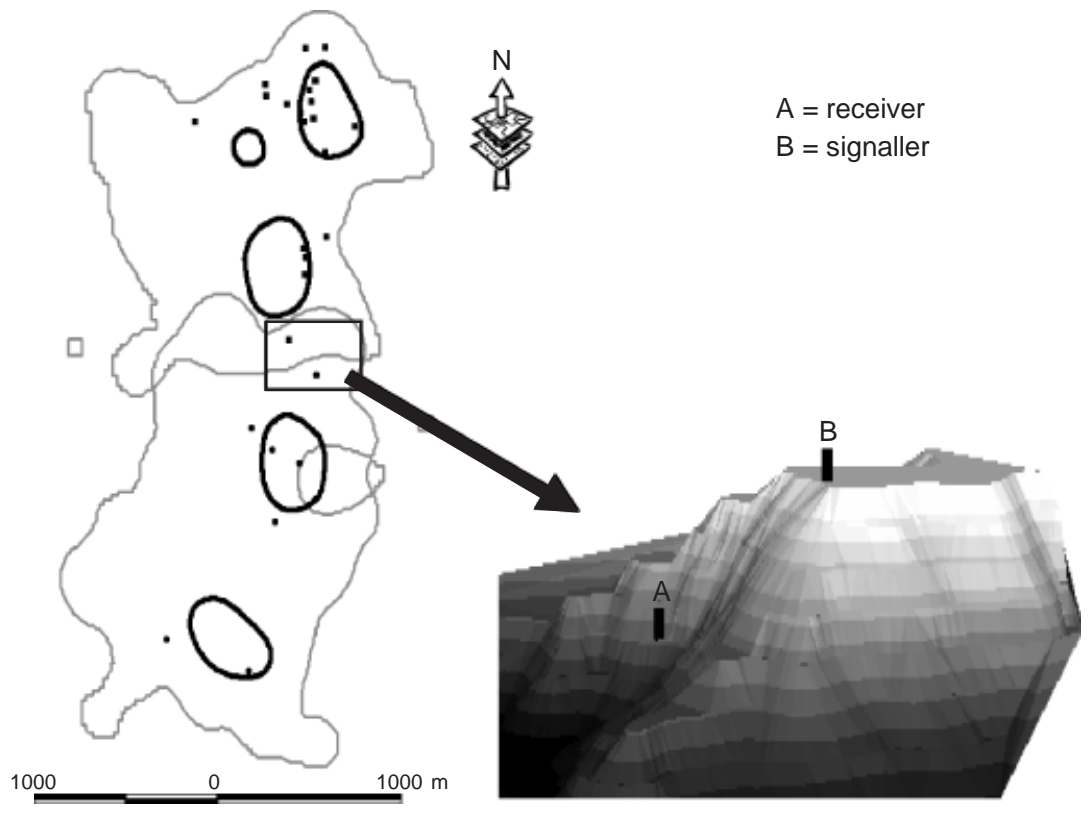

Figure 5 In a social system in which an owner needs to communicate with conspecifics, signallers were located according to best visual and vocal signalling. The 3D representation shows how the signaller principally selected a dominant and high visible position to communicate with its nearest neighbour (i.e. the receiver).
Daily analyses showed that both male and female call displays peaked at sunset and sunrise. We can hypothesize that the higher frequencies of the vocal displays of owls at sunset and sunrise are due to the need for visual contacts between conspecifics. As hypothesized, visual signalling by the white patch on the throat represents an important aspect in the social communication of this not strictly nocturnal bird. In fact (1) many nocturnal species have been found to be habitually active around sunset and sunrise (Martin, 1990), when specific conditions of ambient light could facilitate visual communication by white patches and flash-marks, and (2) several other crepuscular species present achromatic visual signals associated with crepuscular displays, such as Burhinus spp. (Martin, 1990), great snipe Gallinago media (Hoglund, Eriksson \& Lindell, 1992), little bustard Tetrax tetrax (Jiguet \& Bretagnolle, 2001) and nightjars Caprimulgus ruficollis (Aragones, De Reyna \& Recuerda, 1999).

\section{Call-post characteristics}

As hypothesized, locations of eagle owl call posts revealed evidence of a trade-off between social communication inside the core areas (e.g. territorial defence, within-pair communication) and an efficient communication with neighbours. Call posts were located close to both core areas and call posts of neighbouring conspecifics. A similar trade-off was shown by Cerasoli \& Penteriani (1996) for buzzards Buteo buteo, which select their aerial meeting points both close to nests and in specific environmental conditions favouring conspecific communication and flight performances.

Not all areas of the home range are of equal importance to its inhabitants, and certain places are used differently from others (Brown, 1969; Leuthold, 1977). Core areas, which contain essential resources for its owner (Hamilton \& Watt, 1970), were clearly surrounded by call posts of eagle owls. Similar results were reported for Columbian ground squirrels Spermophilus columbianus (Murie \& Harris, 1978), in which male territoriality is stronger within core areas than in the other parts of the home range, and for Whitten (1982), who showed how most of the male's post-dawn song sites of kloss gibbons Hylobates klosii bounded most used areas.

Eagle owls selected the highest points of their home range as call posts, probably to enhance signal transmission (Marten \& Marler, 1977; Beck \& Luke George, 2000) towards neighbouring territorial males and floaters (e.g. to avoid dangerous physical contacts during intrusions; V. Penteriani \& M. M. Delgado, unpubl. results). Eason (1992) suggested that the selection of posts served to increase their visibility during communication and hence to increase the effects of territory defence: the higher the visibility, the more the capability to evict intruders. Because social interactions represent a crucial aspect of animal communication (McGregor, 2005), individuals need to enhance their potential to transfer messages to conspecifics by selecting the best location for this scope. In this context, not only are the highest points crucial, but they are also the posts that enhance communication between neighbours. This could explain why some eagle owl call posts were closer to the call posts of neighbours than core areas.

Our result highlights the need to approach the study of both temporal and spatial behaviour of bird call displays for a better understanding of the patterns and functions of bird vocalizations, as well as the strategies that animals use to increase the efficacy in social communication.

\section{Acknowledgements}

We are grateful to D. Aragones, P. Bartolommei, A. Conejo, P. Delgado, A. Gomez, C. Maggio and G. Penteriani for 
their help with logistics and during fieldwork, and to the landowners for permission to work on their property. We thank the Acebuche of Donana (M. E. Galka, C. Sanchez) and CREA of Seville (J. Bejarano, I. Molina, N. Viqueira) for logistic support and live eagle owls for adult trapping. The first draft of this paper was greatly improved by the criticisms of D. Serrano and A. Rodriguez. Funding for this study was provided by LICOR43 of Diego Zamora S.A. (www.buho-ebd.com), Junta de Andalucia and research project No. CGL2004-02780/BOS of Ministerio de Educacion y Ciencia. We trapped and marked owls under Junta de Andalucia-Consejerı de Medio Ambiente permits No. SCFFS-AFR/GGG RS-260/02 and SCFFS-AFR/ CMM RS-1904/02. During this work M. M. D. was supported by a doctoral grant of the Junta de Andalucia (Consejerı de Educacion y Ciencia). V. P. was supported by a contract of the program 'Incorporacion de Investigadores al Sistema Espanol de Ciencia y Tecnologia’ (CCAA de Andalucia).

\section{References}

Adams, L. \& Davis, S.D. (1967). The internal anatomy of home range. J. Mammal. 48, 529-536.

Alexander, R.D. (1975). Natural selection and specialized chorusing behaviour in acoustical insects. In Insects, science, and society: 35-77. Pimentel, D. (Ed.). New York: Academic Press.

Aragones, J., De Reyna, L.A. \& Recuerda, P. (1999). Visual communication and sexual selection in a nocturnal bird species, Caprimulgus ruficollis, a balance between crypsis and conspicuousness. Wilson Bull. 111, 340-345.

Beck, M.J. \& Luke George, T. (2000). Song post and foraging site characteristics of breeding varied thrushes in northwestern California. Condor 102, 93-103.

Belisle, M. \& St Clair, C.C. (2001). Cumulative effects of barriers on the movements of forest birds. Conserv. Ecol. 5. [Online, URL: http://www.consecol.org/vol5/iss2/art9.]

Belthoff, J.R., Sparks, E.J. \& Ritchison, G. (1993). Home ranges of adult and juvenile eastern screech owls: size, seasonal variation and extent of overlap. J. Raptor Res. 27, 8-15.

Bradbury, JW. \& Vehrencamp, S.L. (1998). Principles of animal communication. Sunderland, MA: Sinauer Associates.

Brown, J.L. (1969). Territorial behavior and population regulation in birds. Wilson Bull. 81, 293-329.

Burt, W.H. (1943). Territoriality and home concepts as applied to mammals. J. Mammal. 24, 346-352.

Cerasoli, M. \& Penteriani, V. (1996). Nest-site and aerial meeting point selection by common buzzards (Buteo buteo) in central Italy. J. Raptor Res. 30, 130-135.

Danielson, B.J. (1992). Habitat selection, interspecific interactions and landscape composition. Evol. Ecol. 6, 399-411.

Davies, N.B. (1989). Sexual conflict and the polygamy threshold. Anim. Behav. 38, 226-234.
Dixon, K.R. \& Chapman, J.A. (1980). Harmonic mean measure of animal activity areas. Ecology 61, 1040-1044.

Eason, P. (1992). Optimization of territory shape in heterogeneous habitats: a field study of the red-capped cardinal (Paroaria gularis). J. Anim. Ecol. 61, 411-424.

Ellner, S.P., McCauley, E., Kendall, B.E., Briggs, C.J., Hosseini, P.R., Wood, S.N., Janssen, A., Sabelis, M.W., Turchin, P., Nisbet, R.M. \& Murdoch, W.M. (2001). Habitat structure and population persistence in an experimental community. Nature 412, 538-543.

Ewer, R.F. (1968). Ethology of mammals. London: Legos Press.

Fretwell, S.D. \& Lucas, J.H.J. (1970). On territorial behaviour and other factors influencing habitat distribution in birds. Acta Biotheor. 19, 16-36.

Gainzarain, J.A., Arambarri, R. \& Rodriguez, A.F. (2000). Breeding density, habitat selection and reproductive rates of the peregrine falcon Falco peregrinus in Alava (northern Spain). Bird Study 47, 225-231.

Galeotti, P., Saino, N., Sacchi, R. \& Møller, A.P. (1997). Song correlates with social context, testosterone and body condition in male barn swallows. Anim. Behav. 53, 687-700.

Hall, M.L. (2000). The function of duetting in magpie-larks: conflict, cooperation, or commitment? Anim. Behav. 60, 667-677.

Hamilton, W.J. III \& Watt, K.E.F. (1970). Refuging. Annu. Rev. Ecol. Syst. 1, 263-286.

Hayne, D.W. (1949). Calculation of home range size. J. Mammal. 30, 1-18.

Hayward, D.G., Hayward, P.H. \& Garton, E.O. (1987). Movements and home range use by boreal owl in central Idaho. In Biology and conservation of Northern Forest owls. Symposium proceedings: 175-184. Nero, R.W., Clark, R.J., Knapton, R.J. \& Hamre, R.H. (Eds). Winnipeg, Manitoba: Fort Collins, CO, US Dept. of Agriculture, Forest Service, Rocky Mountain Forest \& Range Experiment Station.

Hoglund, J., Eriksson, M. \& Lindell, L. (1992). Females of the lek breeding great snipe, Gallinago media, prefer males with white tails. Anim. Behav. 40, 23-32.

Hooge, P.N. \& Eichenlaub, B. (1997). Movement. Animal movement extension to ArcView ver. 3.2. Anchorage, Alaska: Alaska Biological Science Center, U. S. Geological Survey.

Hyman, J. (2003). Countersinging as a signal of aggression in a territorial songbird. Anim. Behav. 65, 1179-1185.

Jenness, J. (2002) Nearest features v. 3.6d extension to ArcView ver 3.2. Flagstaff: Rocky Mountain Research Station, U.S. Forest Service. Wildlife Biologist, GIS Analyst.

Jiguet, F. \& Bretagnolle, V. (2001). Courtship behaviour in a lekking species: individual variations and settlement tactics in male little bustard. Behav. Proc. 55, 107-118.

Kaufmann, J.H. (1962). Ecology and social behaviour of the coati, Nasua nirica on Barro Colorado Island Panama. Univ. Calif. Publ. Zool. 60, 377-389.

Klatt, P.H. \& Ritchison, G. (1993). The duetting behavior of eastern screech-owls. Wilson Bull. 105, 483-489. 
Krebs, J.R., Ashcroft, R. \& Orsdol, K. (1981). Song matching in the great tit Parus major L. Anim. Behav. 29, 918-923.

Leuthold, W. (1977). African ungulates: a comparative review of their ecology and behavioural ecology. New York: Springer-Verlag.

Marler, P. \& Slabbekoorn, H. (2004). Nature's music: the science of birdsong. San Diego: Academic Press.

Marshall, J.T. Jr. (1967). Parallel variation in North and Middle American screech owls. Monogr. West. Found. Vert. Zool. 1, 1-72.

Marten, K. \& Marler, P. (1977). Sound transmission and its significance for animal vocalization: I. Temperate forest habitats. Behav. Ecol. Sociobiol. 2, 271-291.

Martin, G. (1990). Birds by night. London: T \& AD Poyser.

McGregor, P.K. (1993). Signalling in territorial system: a context for individual identification, ranging and eavesdropping. Philos. Trans. Roy. Soc. Ser. B 338, 1-8.

McGregor, P.K. (2005). Communication network. Cambridge: Cambridge University Press.

McGregor, P.K. \& Avery, M.I. (1986). The unsung songs of great tits (Parus major): learning neighbours' song for discrimination. Behav. Ecol. Sociobiol. 18, 311-316.

McGregor, P.K. \& Peake, T. (2000). Communication networks: social environments for receiving and signaling behaviour. Acta Ethol. 2, 71-81.

Melis, C., Cagnacci, F. \& Lovari, S. (2005). Do male deer clump together in the rut? Acta Theriol. 50, 253-262.

Møller, A.P. (1988). Spatial and temporal distribution of song in the yellowhammer Emberiza citrinella. Ethology 78, 321-331.

Molles, L.E. \& Vehrencamp, S.L. (2001). Neighbour recognition by resident males in the banded wren, Thryothorus pleurostictus, a tropical songbird with high song type sharing. Anim. Behav. 61, 119-127.

Moorcroft, P.R., Lewis, M.A. \& Crabtree, R.L. (1999). Home range analysis using a mechanistic home range model. Ecology 80, 1656-1665.

Murie, J.O. \& Harris, M.A. (1978). Territoriality and dominance in male Columbian ground squirrels (Spermophilus columbianus). Can. J. Zool. 56, 2402-2412.

Nicholls, J.A. \& Goldizen, A.W. (2006). Habitat type and density influence vocal signal design in satin bowerbirds. J. Anim. Ecol. 75, 549-558.

Nicholls, T.H. \& Fuller, M.R. (1987). Territorial aspects of barred owl home range and behavior in Minnesota. In Biology and conservation of Northern Forest owls. Symposium proceedings: 121-128. Nero, R.W., Clark, R.J., Knapton, R.J. \& Hamre, R.H. (Eds). Winnipeg, Manitoba: Fort Collins, CO, US Dept. of Agriculture, Forest Service, Rocky Mountain Forest \& Range Experiment Station.

Parker, G.A. (1974). Assessment strategy and the evolution of fighting behaviour. J. Theor. Biol. 47, 223-243.

Penteriani, V. (1996). The eagle owl. Bologna: Calderini Edagricole (in Italian).
Penteriani, V. (1999). Dawn and morning goshawk courtship vocalizations as a method for detecting nest sites. J. Wildlife Mgmt. 63, 511-516.

Penteriani, V. (2001). The annual and diel cycles of goshawk vocalizations at nest sites. J. Raptor Res. 35, 24-30.

Penteriani, V. (2002). Variation in the function of eagle owl vocal behaviour: territorial defence and intra-pair communication? Ethol. Ecol. Evol. 14, 275-281.

Penteriani, V. (2003). Breeding density affects the honesty of bird vocal displays as possible indicators of male/territory quality. Ibis 145, E127-E135.

Penteriani, V., Alonso-Alvarez, C., Delgado, M.M., Sergio, F. \& Ferrer, M. (2006). Brightness variability in the white badge of the eagle owl. J. Avian Biol. 37, 110-116.

Penteriani, V., Delgado, M.M., Alonso-Alvarez, C. \& Sergio, F. (in press). The importance of visual cues for nocturnal species: eagle owls signal by badge brightness. Behav. Ecol. in press.

Penteriani, V., Delgado, M.M., Maggio, C., Aradis, A. \& Sergio, F. (2005). Development of chicks and pre-dispersal behaviour of young in the eagle owl Bubo bubo. Ibis 147, 155-168 (DOI: 10.1111/j.1474-919x.2004.00381.x).

Popp, J.W. (1989). Temporal aspects of singing interactions among territorial ovenbirds (Seiurus atricapillus). Ethology 82, 127-133.

Rodgers, A.R. \& Carr, A.P. (2002). Home range extension to ArcView ver. 3.2. Canada: Ontario Ministry of Natural Resources' Centre for Northern Forest Ecosystem Research in Thunder Bay .

Ruxton, G.D., Armstrong, J.D. \& Humphries, S. (1999). Modelling territorial behaviour of animals in variable environments. Anim. Behav. 58, 113-120.

Samuel, M.D., Pierce, D.J. \& Garton, E.O. (1985). Identifying areas of concentrated use within the home range. J. Anim. Ecol. 54, 711-719.

Silverman, B.W. (1986). Density estimation for statistics and data analysis. London: Chapman \& Hall.

Simpson, B.S. (1985). Effect of location in territory and distance from neighbours on the use of song repertoires by Carolina wrens. Anim. Behav. 33, 793-804.

Stoddard, P.K., Beecher, M.D., Horning, C.L. \& Campbell, S.E. (1991). Recognition of individual neighbours by song in the song sparrow, a species with song repertoires. Behav. Ecol. Sociobiol. 29, 211-215.

Temeles, E.J. (1994). The role of neighbours in territorial systems: when are they 'dear enemies'? Anim. Behav. 47, 339-350.

Voous, K.H. (1988). Owls of the northern hemisphere. London: Wm. Collins Sons and Co.

Whitten, A.J. (1982). Home range use of Kloss gibbons (Hylobates klosii) on Siberut Island, Indonesia. Anim. Behav. 30, 182-198.

Worton, B.J. (1989). Kernel methods for estimating the utilization distribution in home-range studies. Ecology 70, 164-168. 